Hertman, I. \& Ben-Gurion, R. (1958). J. gen. Microbiol. 21, 135-143

\title{
A Study on Pesticin Biosynthesis
}

\author{
BY I. HERTMAN AND RENANA BEN-GURION
}

The Israel Institute for Biological Research, Ness-Ziona, Israel

\begin{abstract}
SUMMARY : Strains of Pasteurella pestis under certain conditions form a bacteriocinlike material, which has been named pesticin. Pesticin formation was induced by ultraviolet irradiation. A chemically defined medium composed of inorganic salts and amino acids supported the synthesis of pesticin by irradiated organisms. The minimal amino acid requirement for pesticin synthesis has been established. For the synthesis of pesticin at $37^{\circ}$ the irradiated organisms required certain amino acids which they did not require at $27^{\circ}$. Bacteria in the stationary phase and actively dividing bacteria were equally able to produce pesticin upon irradiation. Concentrations of chloramphenicol lower than those required for bacteriostasis inhibited pesticin synthesis. Non-pesticin producing mutants of $P$. pestis were obtained by exposure of the bacteria to higher doses of u.v. irradiation than those required for the induction of pesticin formation. These mutants were sensitive to pesticin.
\end{abstract}

It was reported previously (Ben-Gurion \& Hertman, 1958) that ultraviolet (u.v.) irradiated Pasteurella pestis produces a bacteriocin-like material which we named pesticin, when incubated in Proteose peptone broth, while no pesticin was detected after incubation in phosphate buffer. In view of the apparent protein nature of pesticin (Ben-Gurion \& Hertman, 1958) the way of its production can be considered as a problem in protein synthesis.

Pasteurella pestis exhibits different amino acid requirements for growth in defined media at $27^{\circ}$ as compared with $37^{\circ}$ (Hills \& Spurr, 1952; Higuchi \& Carlin, 1958). The synthesis of a number of antigens of $P$. pestis is also known to be temperature dependent (Crumpton \& Davies, 1956; Fox \& Higuchi, 1958). The present study has been mainly concerned with the replacement of the complex proteose peptone medium, in which pesticin synthesis has been observed, by a chemically defined medium.

\section{METHODS}

Organisms. The following strains were used: a streptomycin-resistant mutant of Pasteurella pestis Kimberley strain P; and P. pseudotuberculosis No. $134 \mathrm{C}$.

Media. Proteose peptone broth (Pr3); Proteose peptone agar (Pr3A); blood agar base (BAB); phosphate buffer $\mathrm{m} / 15$. These media were prepared as described previously (Ben-Gurion \& Hertman, 1958).

Casein hydrolysate mineral glucose medium (CHMG) (Englesberg \& Levy, 1954) had the following composition $(\%, \mathrm{w} / \mathrm{v})$ : vitamin-free Casamino acids (Difco), 3; glucose, $0.2 ; \mathrm{NH}_{4} \mathrm{Cl}, 0.1 ; \mathrm{CaCl}_{2}, 0.001 ; \mathrm{FeCl}_{3} .6 \mathrm{H}_{2} \mathrm{O}, 0.00025$; $\mathrm{MgSO}_{4} \cdot 3 \mathrm{H}_{2} \mathrm{O}, 0 \cdot 035 ; \mathrm{KH}_{2} \mathrm{PO}_{4}+\mathrm{Na}_{2} \mathrm{HPO}_{4}$ buffer, $\mathrm{pH} 7,0.025 \mathrm{M}$. The 
Casamino acids were dissolved in distilled water. Glucose was sterilized separately by autoclaving and added aseptically.

Amino acid media. The composition of these media was otherwise that of the CHMG medium, but the vitamin-free Casamino acids were replaced by mixtures of known amino acids. Each amino acid was used in a concentration of $0.004 \%(\mathrm{w} / \mathrm{v})$. The amino acids were purchased from Schwartz Laboratories Inc., Mt. Vernon, N.Y. The purity of the amino acids was ascertained chromatographically.

The conditions of cultivation, count of colony formers, u.v. irradiation were as described previously (Ben-Gurion \& Hertman, 1958).

Pesticin titration. The pesticin was titrated by spotting drops $(0.01 \mathrm{ml}$.) of a series of dilutions of the preparation to be titrated, on the surface of a plate seeded with the indicator strain (Pasteurella pseudotuberculosis). The indicator plates were prepared some minutes before the titration by soaking a filter-paper in a suspension of the strain and leaving the paper on the plates for $5 \mathrm{~min}$. The plates were then incubated at $37^{\circ}$ for $24 \mathrm{hr}$. In this way a series of zones of decreasing inhibition was obtained ranging from complete inhibition through partial inhibition to normal growth. The highest dilution that gave a visible inhibition zone was defined as containing one arbitrary unit/ml. (A.U./ml.).

Pesticin biosynthesis. In the general procedure for observing pesticin synthesis Pasteurella pestis was grown in Pr3 broth for $18 \mathrm{hr}$. at $27^{\circ}$ until a concentration of $10^{7} \mathrm{bacteria} / \mathrm{ml}$. was reached. The growing organisms were washed twice, diluted in phosphate buffer to a concentration of about $10^{8}$ organisms $/ \mathrm{ml}$. and u.v. irradiated for $60 \mathrm{sec}$. Samples of the irradiated bacterial suspension were diluted $1 / 5$ in the amino acid media and incubated for $4 \mathrm{hr}$. at the desired temperature. Pesticin titrations and bacterial counts were performed during and after the incubation period. In experiments in which both bacterial growth and pesticin synthesis were determined only freshly harvested organisms were used. In experiments where only pesticin synthesis was determined the bacterial suspension could be stored at $5^{\circ}$ for 2 days.

\section{RESULTS}

Pesticin synthesis in a complete amino acid medium

Preliminary experiments showed that the CHMG medium was as suitable as Pr3 broth for pesticin production by irradiated bacteria. When the vitaminfree Casamino acids were replaced by a mixture of 18 amino acids ( $\mathrm{L}$-aspartic acid, L-proline, L-lysine, L-threonine, L-glutamic acid, L-cysteine hydrochloride, L-alanine, L-serine, L-tryptophan, L-histidine, L-methionine, L-valine, L-arginine, L-leucine, L-isoleucine, glycine, L-phenylalanine and L-tyrosine) pesticin synthesis proceeded to the same extent (pesticin yield $750 \mathrm{A.U} . / \mathrm{ml}$.) as in the Pr3 broth. No quantitative differences were found in pesticin synthesis at $27^{\circ}$ and $37^{\circ}$. This medium was, therefore, called the complete amino acid medium (CAA).

To determine which amino acids are essential for pesticin synthesis, 18 media 
were made in each of which one of the above amino acids was omitted from the CAA medium. Irradiated bacteria were transferred to these media as well as to the CAA medium, and pesticin synthesis at $27^{\circ}$ and $37^{\circ}$ measured. The results are presented in Table 1. The omission of methionine, phenylalanine, valine or glycine inhibited pesticin synthesis. Leucine and isoleucine were required at $37^{\circ}$ but not at $27^{\circ}$.

\section{Table 1. Pesticin biosynthesis in CAA medium from which one of the 18 amino acids was omitted}

Samples of $10^{8}$ Pasteurella pestis organisms $/ \mathrm{ml}$. were diluted $1 / 5$ in 19 amino acid media. Pesticin synthesis after incubation at $27^{\circ}$ and $37^{\circ}$ for $4 \mathrm{hr}$. was measured by pesticin titration.

\begin{tabular}{|c|c|c|}
\hline \multirow{2}{*}{$\begin{array}{l}\text { The amino acid omitted } \\
\text { from CAA medium }\end{array}$} & \multicolumn{2}{|c|}{ Incubation temperature } \\
\hline & \multicolumn{2}{|c|}{$\begin{array}{l}\text { Pesticin conen. } \\
\text { (arbitrary units/ml.) }\end{array}$} \\
\hline None (CAA medium) & 500 & 500 \\
\hline L-Methionine & 2 & 2 \\
\hline Glycine & 10 & 10 \\
\hline L-Phenylalanine & 10 & 10 \\
\hline L-Valine & 10 & 2 \\
\hline L-Lysine & 500 & 500 \\
\hline L-Leucine & 500 & 10 \\
\hline L-Isoleucine & 500 & 2 \\
\hline
\end{tabular}

Omission of L-aspartic acid, L-proline, L-glutamic acid, L-cysteine (HCl), L-serine, L-histidine, L-threonine, L-tyrosine, L-arginine, L-alanine and L-tryptophan, did not decrease the pesticin yield at either temperature.

\section{Minimal amino acid medium for pesticin synthesis}

To determine the minimal amino acid requirement for pesticin synthesis a medium was developed containing the six amino acids found above to be essential (methionine, valine, phenylalanine, glycine, leucine and isoleucine) This medium did not support pesticin synthesis, but on addition of lysine and arginine synthesis did take place. The eight amino acids methionine, phenylalanine, glycine, valine, leucine, isoleucine, lysine and arginine together were thus found to be essential for pesticin synthesis. The medium containing these amino acids was called the minimal amino acids medium (MAA). Arginine could be omitted at $27^{\circ}$ without decreasing the yield of pesticin. Cysteine added to MAA medium doubled the pesticin production. Addition of alanine increased the pesticin yield in MAA medium at $27^{\circ}$. The yield of pesticin in MAA medium was $10 \%$ of the yield in the CAA medium containing the 18 amino acids which are found in casein hydrolysate. Quantitative differences were found between pesticin production at $27^{\circ}$ and $37^{\circ}$. The yield was always considerably lower at $37^{\circ}$ than at $27^{\circ}$. The omission of phenylalanine, lysine, glycine, valine, leucine, isoleucine or methionine from the cysteine-supplemented MAA medium inhibited pesticin synthesis at either temperature. The 
results of these experiments are presented graphically in Fig. 1. When phenylalanine, valine and methionine were replaced by their $D$-isomers in MAA medium, no pesticin synthesis was observed.

\section{The role of glucose in pesticin synthesis}

Experiments were performed to establish whether the addition of glucose was essential for pesticin synthesis. Glucose-depleted bacteria cells were prepared by growing Pasteurella pestis for $48 \mathrm{hr}$. at $27^{\circ}$ in glucose-free casein hydrolysate medium (CHM). These organisms were seeded again into CHM medium and incubated for $18 \mathrm{hr}$. at $27^{\circ}$. The actively growing organisms were harvested, washed, and pesticin synthesis in CAA medium and in cysteinesupplemented MAA medium was measured. Pesticin synthesis proceeded in the absence of glucose to the same extent as in the glucose containing controls (Table 2).

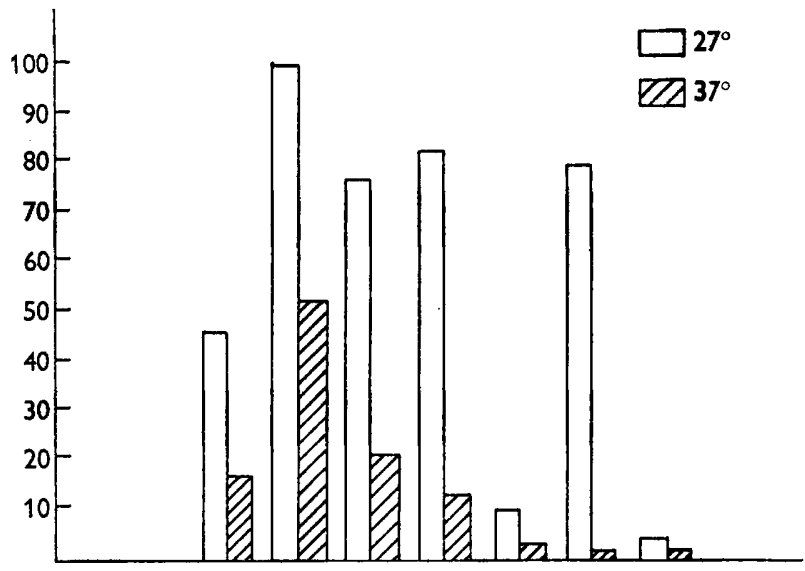

Fig. 1. Minimal amino acid requirements for pesticin biosynthesis by u.v.-irradiated Pasteurella pestis cells at $27^{\circ}$ and $37^{\circ}$. Each column represents the average of ten experiments. The omission of L-lysine, glycine, L-valine, L-leucine, L-isoleucine, L-phenylalanine or L-methionine from the cysteine-supplemented MAA medium inhibited pesticin synthesis at either temperature.

L-Valine
L-Phenylalanine
L-Arginine
L-Methionine
L-Lysine
L-Leucine
L-Isoleucine
L-Alanine
L-Cysteine
Glycine

$\begin{array}{lll}+ & + & + \\ + & + & + \\ + & + & + \\ + & + & + \\ + & + & + \\ + & + & + \\ + & + & + \\ - & + & + \\ - & + & + \\ + & + & +\end{array}$

$\begin{array}{lllll}+ & + & + & + & + \\ + & + & + & + & + \\ + & + & + & - & + \\ + & + & - & + & - \\ + & + & + & + & + \\ + & + & + & + & + \\ + & + & + & + & + \\ + & + & + & - & - \\ + & + & - & + & + \\ + & + & + & + & +\end{array}$

Amino acid requirement for growth of Pasteurella pestis, Kimberley strain $\boldsymbol{P}$

Pasteurella pestis was grown on CHMG slants (CHMG plus $2 \%(\mathrm{w} / \mathrm{v})$ agar) at $27^{\circ}$ for $24 \mathrm{hr}$. The bacteria were harvested and washed twice with phosphate buffer. Growth in amino acid media was determined by inoculating $\boldsymbol{P}$. pestis 
into $3 \mathrm{ml}$. of medium in duplicate test tubes. The final concentration of the inoculum was $10^{6} \mathrm{bacteria} / \mathrm{ml}$. The tubes were incubated on a shaker for $72 \mathrm{hr}$. at $27^{\circ}$ and growth was measured by count of colony formers. Growth of $\boldsymbol{P}$. pestis was observed in the presence of six amino acids (methionine, phenylalanine, valine, isoleucine, cysteine and glycine). This medium did not support pesticin synthesis. Growth of $\boldsymbol{P}$. pestis was observed also in the MAA medium. Addition of cysteine to this medium stimulated the bacterial growth (Table 3).

Table 2. Pesticin biosynthesis in amino acid media with and without glucose addition

Samples of $10^{8}$ u.v.-irradiated Pasteurella pestis organisms $/ \mathrm{ml}$. were diluted $1 / 5$ in the complete amino acid (CAA) medium and in the L-cysteine-supplemented minimal amino acid medium (CMAA), with and without $0.2 \%(u / v)$ glucose. Pesticin synthesis was measured by pesticin titration after the $4 \mathrm{hr}$. incubation period. At zero time, no pesticin was detected.

$\begin{array}{cccc}\text { Medium } & \begin{array}{c}\text { Presence or } \\ \text { absence of } \\ \mathbf{0 . 2} \% \text { glucose }\end{array} & \begin{array}{c}\text { Incubation } \\ \text { temperature } \\ \left({ }^{\circ} \mathrm{C}\right)\end{array} & \begin{array}{c}\text { Pesticin conc. } \\ \text { (arbitrary } \\ \text { units } / \mathrm{ml} \text { ) }\end{array} \\ \text { CAA } & + & \mathbf{2 7} & \mathbf{5 0 0} \\ \text { CAA } & - & \mathbf{2 7} & \mathbf{7 5 0} \\ \text { CAA } & + & \mathbf{3 7} & \mathbf{5 0 0} \\ \text { CAA } & - & \mathbf{3 7} & \mathbf{5 0 0} \\ \text { CMAA } & + & \mathbf{2 7} & \mathbf{1 5 0} \\ \text { CMAA } & - & 27 & 100 \\ \text { CMAA } & + & 37 & 50 \\ \text { CMAA } & - & 37 & 50\end{array}$

Table 3. Amino acid requirement for growth of Pasteurella pestis Kimberley strain $\boldsymbol{P}$

The organisms were inoculated on a basal amino acid medium containing the following amino acids: L-phenylalanine, $\mathrm{L}$-valine, L-isoleucine and L-methionine. To this medium amino acids were added as indicated. Final concentration of the inoculum was $9 \times 10^{5}$ bacteria $/ \mathrm{ml}$. No growth was observed upon single addition of L-leucine, L-lysine, L-arginine or L-cysteine to the basal amino acid medium.

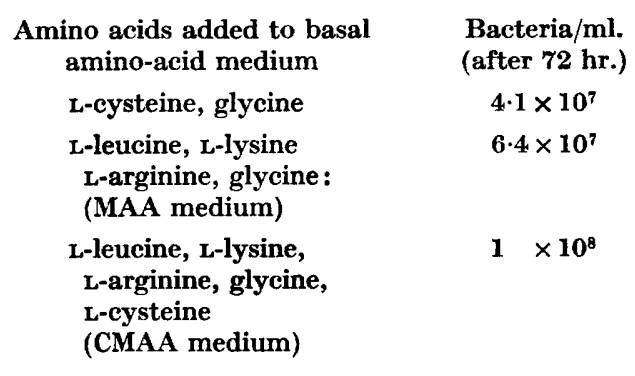

\section{Bacterial growth and pesticin synthesis}

Freshly harvested and washed organisms in the logarithmic phase of growth were diluted to a concentration of about $10^{8} \mathrm{bacteria} / \mathrm{ml}$. and the suspension divided into two parts. One part was immediately suspended in an amino acid medium, and the growth was followed by colony count during incubation at $27^{\circ}$ for $4 \mathrm{hr}$. The other part of the suspension was u.v.-irradiated and then suspended in the same medium; growth and pesticin synthesis were followed 
simultaneously during incubation at $27^{\circ}$ for $4 \mathrm{hr}$. A typical experiment comparing growth and pesticin synthesis in CAA and MAA media is presented in Fig. 2. The rate of growth of non-irradiated bacteria was higher in the CAA medium than in the MAA medium. The rate of pesticin synthesis by irradiated bacteria was also higher in the CAA medium. The bacteria which survived irradiation grew more slowly in CAA medium than those which were not irradiated; in MAA medium the difference was not appreciable. In order to establish whether the bacteria irradiated in the stationary phase of growth are able to synthesize pesticin a culture of Pasteurella pestis was harvested after

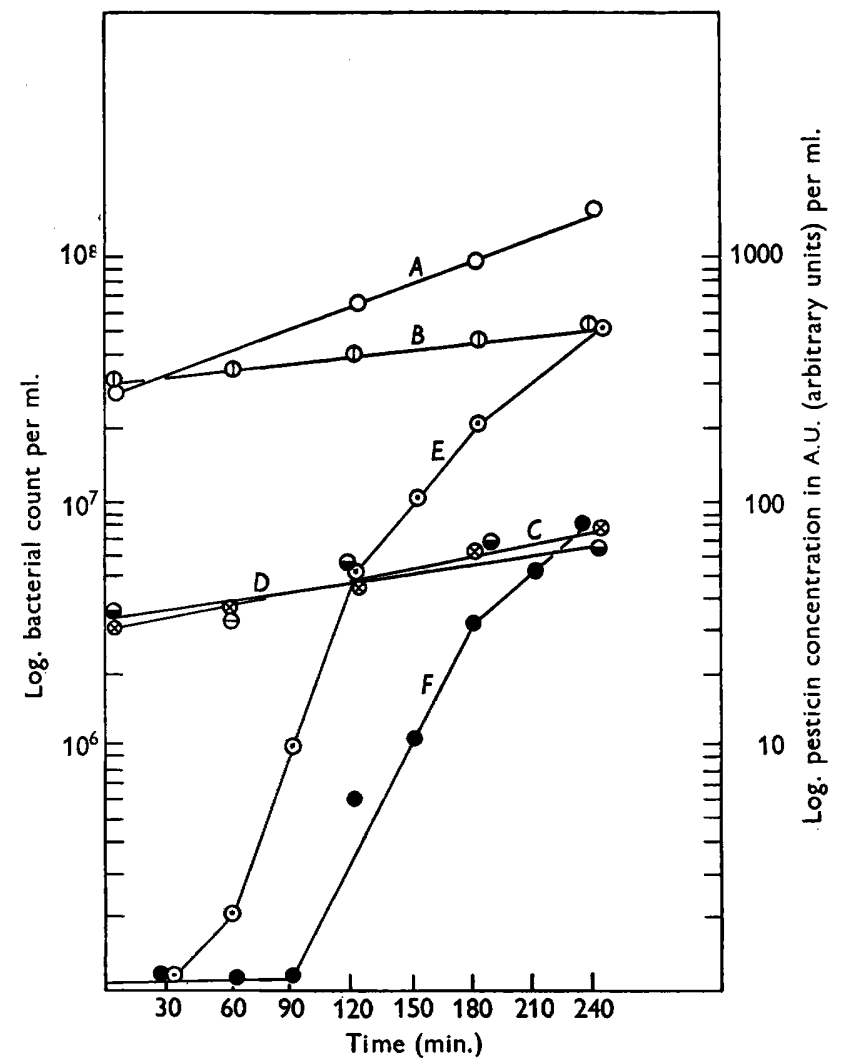

Fig. 2. Bacterial growth and pesticin biosynthesis by Pasteurella pestis, strain Kimberley $P$, in the logarithmic phase of growth in CAA and MAA medium at $27^{\circ}$ and $37^{\circ} . A$, growth of non-irradiated bacteria in CAA medium; $B$, growth of non-irradiated bacteria in MAA medium; $C$, growth of irradiated bacteria in CAA medium; $D$, growth of irradiated bacteria in MAA medium; $E$, pesticin biosynthesis in CAA medium; $F$, pesticin biosynthesis in MAA medium.

incubation for 3 days at $27^{\circ}$. Growth of the non-irradiated bacteria and growth and pesticin synthesis of the irradiated bacteria were measured. Though no growth of non-irradiated bacteria was detected by colony count in CAA medium, pesticin synthesis proceeded normally in the CAA and MAA media. A typical experiment is presented in Fig. 3. 
The effect of chloramphenicol on pesticin synthesis

The effect of chloramphenicol, an inhibitor of protein synthesis (Gale \& Folkes, 1953; Wisseman, Smadel, Hahn \& Happs, 1954), on pesticin synthesis was tested. Irradiated Pasteurella pestis in the logarithmic phase of growth was suspended in CAA medium containing increasing concentrations of Synthomycetin U.S.P. (trade name for chloramphenicol; Abic, Ramat-Gan, Israel) and pesticin synthesis was measured after incubation at $27^{\circ}$ and $37^{\circ}$ for $4 \mathrm{hr}$. The effect of the same concentrations of chloramphenicol (which was

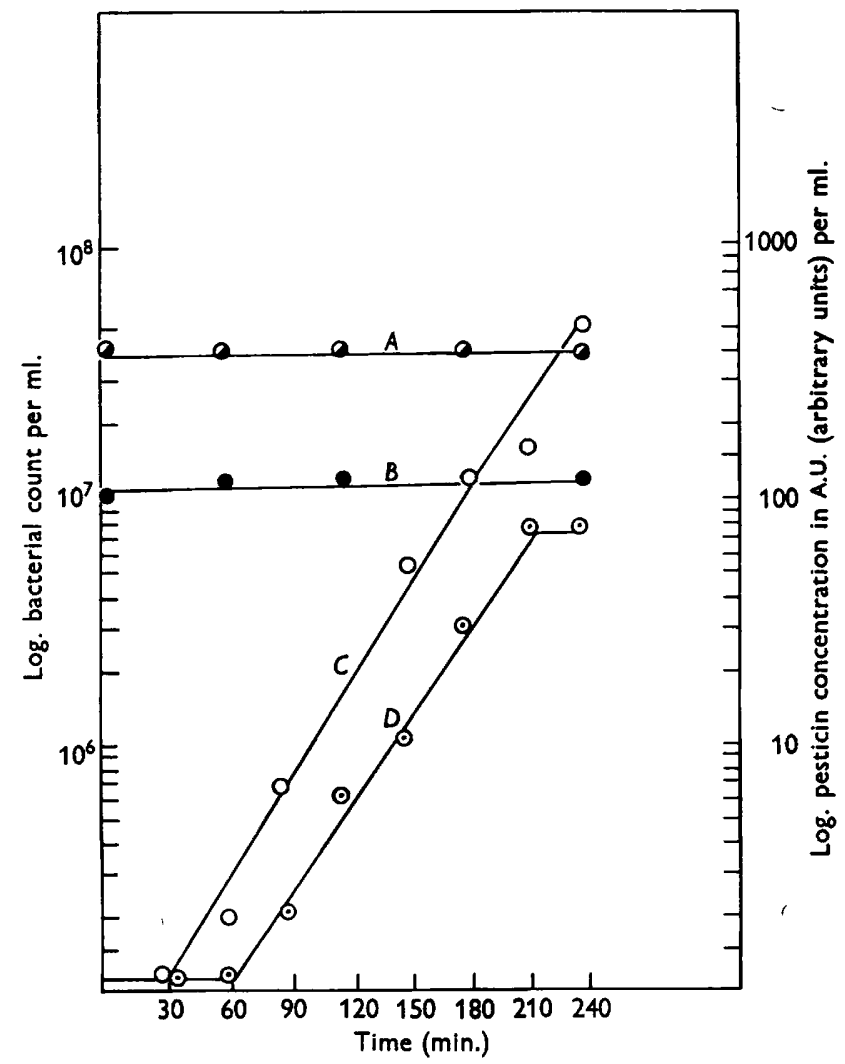

Fig. 3. Bacterial growth and pesticin biosynthesis by Pasteurella pestis, strain Kimberley $\mathbf{P}$ at the end of the logarithmic phase of growth in CAA and MAA medium at $27^{\circ}$ and $37^{\circ}$. $A$, growth of non-irradiated organisms in CAA medium; $B$, growth of irradiated organisms in CAA medium; $C$, pesticin biosynthesis in CAA medium; $D$, pesticin biosynthesis in MAA medium.

below the concentration which caused bacteriostasis) on the growth of nonirradiated bacteria during the same incubation period at $27^{\circ}$ and $37^{\circ}$ was determined. Control measurements of growth and pesticin synthesis in CAA medium were performed. The results are shown in Table 4. It can be seen that similar concentrations of chloramphenicol inhibited both the growth of non-irradiated bacteria and pesticin synthesis by the irradiated bacteria. Chloramphenicol 
at $1 \mu \mathrm{g} . / \mathrm{ml}$. exerted a markedly inhibitory effect on pesticin synthesis at $27^{\circ}$ and $37^{\circ}$.

Table 4. Comparison of inhibitory effect of graded low chloramphenicol concentrations on: (a) pesticin biosynthesis by irradiated Pasteurella pestis; $(b)$ the growth of non-irradiated bacteria

Samples of u.v.-irradiated $P$. pestis $10^{8}$ bacteria $/ \mathrm{ml}$. were diluted $1 / 5$ in CAA medium containing low chloramphenicol concentrations and pesticin biosynthesis after $4 \mathrm{hr}$. incubation was measured. Growth of non-irradiated bacteria at the same chloramphenicol concentrations was determined by colony count. CAA medium without chloramphenicol was used for control determination of pesticin yield and bacterial growth.

\begin{tabular}{|c|c|c|c|c|}
\hline \multirow{2}{*}{$\begin{array}{l}\text { Chloramphenicol } \\
(\mu \mathrm{g} . / \mathrm{ml} .)\end{array}$} & \multicolumn{2}{|c|}{$\begin{array}{c}\text { Irradiated } P \cdot \text { pestis } \\
\text { Incubation temperature }\end{array}$} & \multicolumn{2}{|c|}{$\begin{array}{l}\text { Non-irradiated } P \text {. pestis } \\
\text { Incubation temperature }\end{array}$} \\
\hline & $\begin{array}{r}\mathbf{2 7}^{\circ} \\
\text { Pesticin }\end{array}$ & $\begin{array}{c}37^{\circ} \\
\text { control) }\end{array}$ & $\begin{array}{r}27^{\circ} \\
\text { Bacterial }\end{array}$ & $\begin{array}{l}37^{\circ} \\
\text { f control) }\end{array}$ \\
\hline 0.0 & 100 & 100 & 100 & 100 \\
\hline 0.5 & 100 & 100 & 100 & 100 \\
\hline $1 \cdot 0$ & 44 & $\mathbf{3 3}$ & 100 & 83 \\
\hline $2 \cdot 0$ & 25 & 7 & 74 & 46 \\
\hline 3.0 & 10 & 0 & 47 & 36 \\
\hline
\end{tabular}

Non-pesticinogenic mutants of Pasteurella pestis

To test whether non-pesticinogenic mutants of the Kimberley strain of Pasteurella pestis could be obtained, the following experiments were performed. $\boldsymbol{P}$. pestis (streptomycin-resistant) grown in $\operatorname{Pr} 3$ broth to a concentration of $10^{8}$ bacteria/ml. were u.v.-irradiated for $5 \mathrm{~min}$. This dose killed $95 \%$ of the organisms. The irradiated bacteria were plated on $\operatorname{Pr} 3 A$ plates and tested for pesticinogenic properties by the double layer method (Ben-Gurion \& Hertman, 1958). Streptomycin-sensitive $P$. pseudotuberculosis was used as indicator. Colonies which did not produce pesticin were removed with a bacteriological loop and streaked on $\mathrm{BAB}$ medium containing $500 \mu \mathrm{g}$. streptomycin $/ \mathrm{ml}$. The developed colonies were streaked once more on streptomycin-containing BAB medium. The strains thus obtained were tested for rhamnose fermentation, pesticin production and pesticin sensitivity. Three independent mutants were isolated by plating $10^{5}$ bacteria. These mutants were streptomycinresistant and did not ferment rhamnose and were thus distinguished from the $\boldsymbol{P}$. pseudotuberculosis indicator strain. These non-pesticinogenic mutants were sensitive to pesticin.

\section{DISCUSSION}

A defined amino acid medium has been developed which supports pesticin production by u.v.-irradiated Pasteurella pestis. In view of the requirement for amino acids and the sensitivity of the system to chloramphenicol, bacteriocinogenesis by $\boldsymbol{P}$. pestis may represent a de novo protein synthesis.

Experiments thus far have not revealed whether the described amino acid requirements are specific for the synthesis of pesticin or represent general requirements for protein synthesis by the bacterial cell. A higher yield of pesticin was obtained in the CAA and CMAA media than in the MAA medium. 
The former media also supported a higher rate of growth of non-irradiated bacteria. These observations indicate that the amino acids may be required for the general synthetic activity of the bacteria and only indirectly influence pesticin synthesis. Further proof of the dependence of pesticin synthesis upon the general synthesizing capacity of the bacterial cell may be found in the observation that maximum pesticin production occurred in a medium which supported abundant bacterial growth from a small inoculum and which thus could replace more complex media, as reported by other authors (Rockenmacher, James \& Elberg, 1952). On the other hand, it may be concluded that the amino acid requirements described in this work are specific directly for pesticin synthesis, since the latter was observed also in bacteria in the stationary phase of growth. Also, Pasteurella pestis can be grown in a defined medium containing six amino acids (phenylalanine, valine, methionine, isoleucine, cysteine and glycine), which does not support pesticin synthesis. No decision can yet be reached between these two alternatives. Media in which maximum pesticin synthesis was not reached gave a lower production at $37^{\circ}$ than at $27^{\circ}$. These observations indicate more efficient protein synthesis at $27^{\circ}$ than at $37^{\circ}$. The amino acids supplied to the defined media were an adequate source of energy, and no addition of glucose was needed. Mutants of $P$. pestis which lost the pesticinogenic property became sensitive to the pesticin they originally produced. A similar behaviour has been observed for the colicinogenic strains of Escherichia coli (Fredericq, 1948).

\section{REFERENCES}

Ben-Gurion, R. \& Hertman, I. (1958). Bacteriocin-like material produced by Pasteurella pestis. J. gen. Microbiol. 19, 289.

Crumpton, M. J. \& Davies, D. A. L. (1956). An antigenic analysis of Pasteurella pestis by diffusion antigens and antibodies in agar. Proc. Roy. Soc. B, 145, 109.

Englesberg, E. \& Levy, J. B. (1954). Studies on immunisation against plague. 6. Growth of Pasteurella pestis and the production of the envelope and other soluble antigens in a casein hydrolysate mineral glucose medium. J.Bact.67, 438.

Fox, E. N. \& Higuchi, K. (1958). Synthesis of the fraction I antigenic protein by Pasteurella pestis. J. Bact. 75, 209.

FredericQ, P. (1948). Antibiotiques réciproques chez les Enterobactériaceae. Rev. belge Path. (Suppl. 4), 19, 1.

Gale, E. F. \& Folkes, J. P. (1953). The assimilation of amino acids by bacteria. 15. Actions of antibiotics on nucleic acid and protein synthesis in Staphylococcus aureus. Biochem. J. 53, 493.

Hrguchi, K. \& Carlin, C. E. (1958). Studies on the nutrition and physiology of Pasteurella pestis. 2. A defined medium for the growth of Pasteurella pestis. J. Bact. 75, 409.

Hills, G. M. \& Spurr, E. D. (1952). The effect of temperature on the nutritional requirements of Pasteurella pestis. J. gen. Microbiol. 6, 64 .

Rockenmacher, M., James, H. A. \& Elberg, S. S. (1952). Studies on the nutrition and physiology of Pasteurella pestis. J. Bact. 67, 662 .

Wisseman, C. L., Smadex, J. E., Hahn, F. E. \& Happs, H. E. (1954). The mode of action of chloramphenicol. 1. Action of chloramphenicol on the assimilation of ammonia and on the synthesis of protein and nucleic acid in Escherichia coli. J. Bact. 67, 662 .

(Received 30 December 1958) 